\title{
Evaluation of electrocardiogram and echocardiographic characteristics of pre-and post-operation of His bundle pacing: A comprehensive review and meta-analysis
}

\author{
Mingzhu Li*(D), Fei Ren**(D), Jing Tian** (D), Kai Yang* (D), Jie Zhang*** (D), \\ Hejian Song* (D), Delu Yin* (D), Steven Cui ${ }^{1}$ (D)
}

Departments of *Cardiology, and **Science and Education, ***Ultrasonics, The Affiliated Lianyungang Hospital of Xuzhou Medical University; Lianyungang-China

${ }^{1}$ Department of Orthopedic Surgery, University of Otago; Christchurch-New Zealand

\section{ABSTRACT}

Objective: Although His bundle pacing (HBP) has shown an improved therapeutic effect than conventional pacing in terms of reducing cardiovascular mortality, the basic characteristics of HBP has not been defined systematically. Therefore, a systematical review and meta-analysis on the HBP characteristics can be timely and favorable. In this study, we aimed to clarify the electrocardiogram and echocardiographic characteristics of the pre- and post-operation of HBP.

Methods: Patients with HBP were exclusively included in this study. By evaluating their electrocardiogram characteristics, echocardiographic parameters, and cardiac function, the therapeutic effect of HBP was assessed.

Results: A total of 23 studies were included in the analysis. The overall implant success rate for HBP was $83.64 \%$. After HBP treatment, the paced QRS duration dropped from $147.73 \pm 19.46 \mathrm{~ms}$ to $116.84 \pm 17.32 \mathrm{~ms}(\mathrm{p}<0.001)$. Left ventricular ejection fraction (LVEF) increased from $34.87 \% \pm 9.62 \%$ to $46.40 \% \pm 9.64 \%$ ( $p<0.001$ ), and NYHA functional class improved from $2.90 \pm 0.57$ to $1.78 \pm 0.58$ within the HBP group (SMD-2.09; $95 \%$ Cl-2.53,-1.64, $\mathrm{p}<0.001)$.

Conclusion: HBP can significantly reduce the QRS duration, resulting in improvement of cardiac function in most patients. In addition, this approach is applicable to most patients without limitations.

Keywords: His bundle pacing, electrocardiogram, echocardiogram, cardiac function, meta-analysis

Cite this article as: Li M, Ren F, Tian J, Yang K, Zhang J, Song H, et al. Evaluation of electrocardiogram and echocardiographic characteristics of pre-and postoperation of His bundle pacing: A comprehensive review and meta-analysis. Anatol J Cardiol 2021; 25: 845-57.

\section{Introduction}

Myocardial remodeling (MR) often occurs in patients with cardiovascular diseases, resulting from an abnormal neurohumoral regulation owing to the heart failure (HF) $(1,2)$. Normally, after the infarction, heart tissue goes through macro and microremodeling. Non-elastic fibrotic tissue replaces the healthy myocardium, and the architecture of the left ventricle deforms from an efficient elliptical shape into a spherical chamber, resulting in alteration of ventricular dilatation (3). Often these changes lead to heart dysfunction in vulnerable patients, developing into HF (4).

Cardiac resynchronization therapy (CRT) has been clinically used to treat $\mathrm{HF}$ in patients with impaired left ventricular function or a wide QRS complex (5). Previous studies indicate that CRT could improve cardiac structure and function and slow the pro-

Address for Correspondence: Mingzhu Li, MD, Department of Cardiology, 


\section{HIGHLIGHTS}

- Indices included QRS duration, left ventricular ejection fraction, New York Heart Association, left ventricular end-diastolic diameter, left ventricular end-systolic diameter, 6 minute walk distance, and brain natriuretic peptide before and after His bundle pacing (HBP) were clarified comprehensively, which could be substantial evidence of cardiac reverse remodeling.

- High success rates $(83.64 \%$ ) demonstrated the applicability of HBP.

- The correlation of difference values between QRSd and LVEF were assessed for the first time after HBP, which indicated that the conduction pathway, especially physiologic pacing could improve cardiac function.

gression of $\mathrm{HF}$, resulting in an improvement in the quality of life (6). The mechanism associated with the process of remodeling mainly is "asynchrony." Atrioventricular delay leads to delay of ventricular contraction and decrease of diastolic filling, the left ventricle maintains its function through a compensatory response (FrankStarling mechanism) at an early stage. Systolic mitral regurgitation also occurs as a result of mitral valve ring dilation. CRT modifies functional blocks, which are associated with mechanical dyssynchrony. Compared with optimal pharmacological therapy (OPT), CRT leads to a $20 \%$ reduction in death or hospitalization (7).

However, some studies (8) have demonstrated that CRT could potentially increase the risk of pro-arrhythmic effects. It may be caused by reversal of the normal activation sequence by epicardial pacing, which leads to the prolongation of the OT interval and transmural dispersion of repolarization (TDR), creating a substrate and trigger for recurrent arrhythmias (9-11). Therefore, the understanding of the electrophysiological mechanism has gained importance in the field of cardiac electrophysiology. The understanding of His Purkinje system (HPS) based on physiological pacing has particularly attracted significant research interest owing to its wide clinical usage (12). The activation of HBP by HPS can mimic rapid parallel ventricular activation and has been a new clinical strategy, demonstrating an improved therapeutic effect. To date, the electrocardiogram and echocardiographic characteristics of the preHBP and postHBP has yet to be systemically defined. Therefore, in this study, we aimed to provide a clear description of the electrocardiogram and echocardiographic characteristics, helping clinicians have a better understanding of HBP.

\section{Methods}

This meta-analysis was performed according to the Preferred Reporting Items for Systematic Reviews and MetaAnalyses guidelines (13).

\section{Search strategy and selection criteria}

Databases including PubMed, EMBase, Cochrane library, Web of science, CNKI, and Wanfang data were used, and keywords including His bundle pacing, cardiac failure, cardiac dysfunction, cardiac remodeling were selected to screen the literature. Furthermore, the literature was further filtrated using the following criteria: (1) the study object was human; (2) exclusive definition of successful HBP, including direct $\mathrm{HBP}$ and paraHBP; (3) effective parameters include QRS duration (ORSd), left ventricular ejection fraction (LVEF), New York Heart Association (NYHA), left ventricular end-diastolic diameter (LVEDD), left ventricular end-systolic diameter (LVESD), left arterial dimension (LA), 6-minute walk distance (6MWD), and brain natriuretic peptide (BNP). The exclusion criteria included incomplete results; case reports, conference abstracts, reviews, editorials, or notes; missing specific parameters listed in the inclusion criteria; and animal experiments. The search strategy and exclusion criteria are presented in Figure 1.

\section{Data extraction and quality assessment}

Data extraction was performed independently by 2 researchers. The following data were extracted, including first author's name, study publication year, design [randomized control trial (RCT), cohort study, and observational study], patient characteristics (sex, age), sample size, setting (QRSd, LVEF), interventions, and follow-up period. In addition, indices including echocardiographic indices (LVESD, LVEDD, LA, MR) and cardiac functional capacity (NYHA functional class, 6MWD) were further selected with baseline and post-intervention data, and the difference of the selected indices between preHBP and postHBP were identified.

The methodological qualities of the RCTs were assessed by the Cochrane Collaboration bias risk tools for random sequence generation, allocation concealment, blinding, incomplete outcome data, selective outcome reporting, and other potential sources of bias. Observational trials or cohort studies were assessed using key study design components presented in the Newcastle-Ottawa scale.

\section{Data synthesis and statistical analyses}

Dichotomous variables were reported as proportions, and continuous variables were primarily presented as mean \pm standard deviation. The standard mean differences (SMD) with $95 \%$ confidence intervals for the indices were plotted as forest plots. Publication bias risk was estimated using funnel plot and Egger's test. Pooled analyses were implemented through fixedeffect models, whereas random-effect models were applied when significant heterogeneity was established across studies. Heterogeneity between studies was assessed using the 0 statistic, and its extent was calculated by the $\mathrm{I}^{2}$ test to determine if variability between studies resulted from heterogeneity or chance. The effect of each study on the overall therapeutic effect was assessed by sensitivity analysis using the leave-oneout approach. Meta-analyses were performed using Stata soft- 

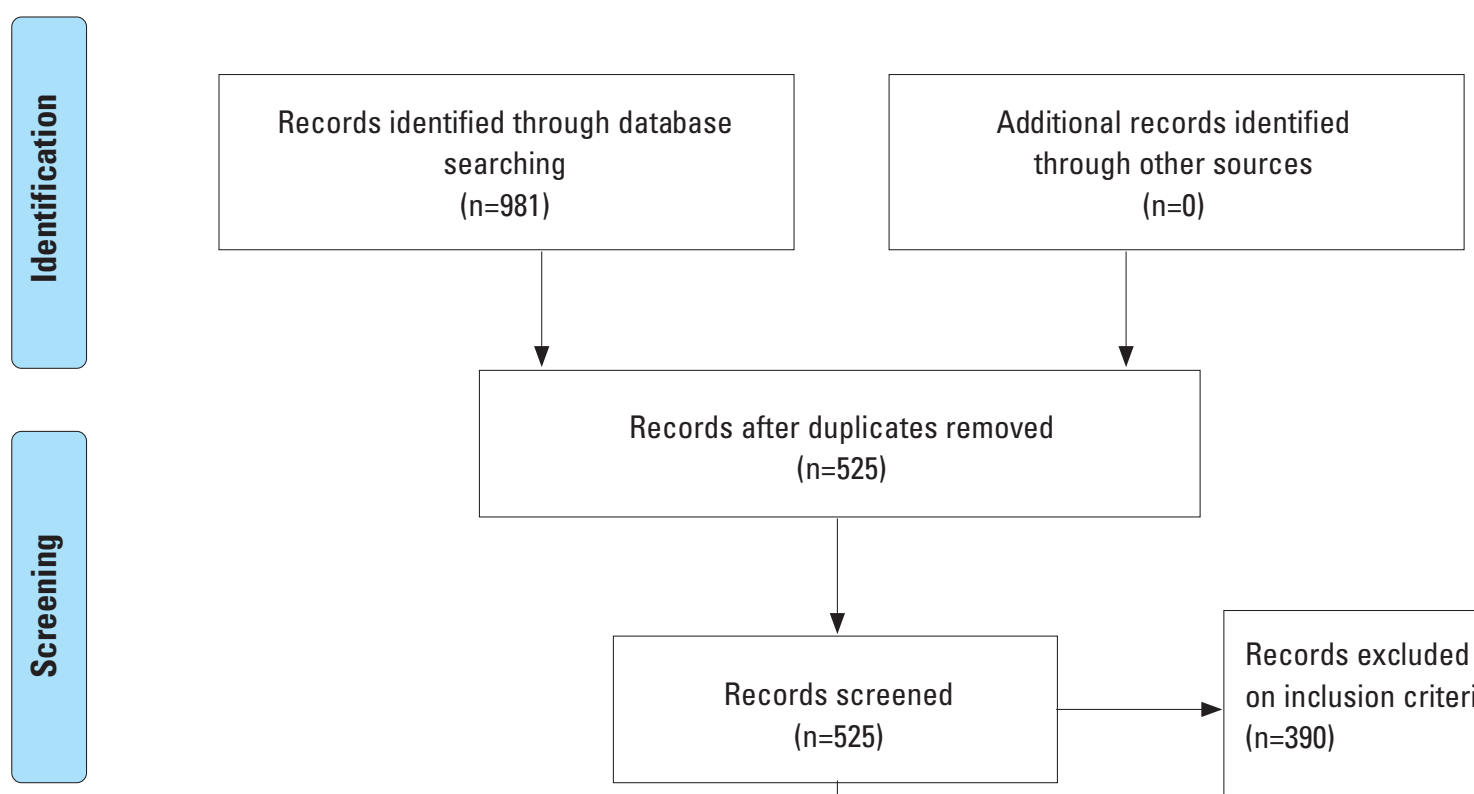

Records after duplicates removed $(n=525)$
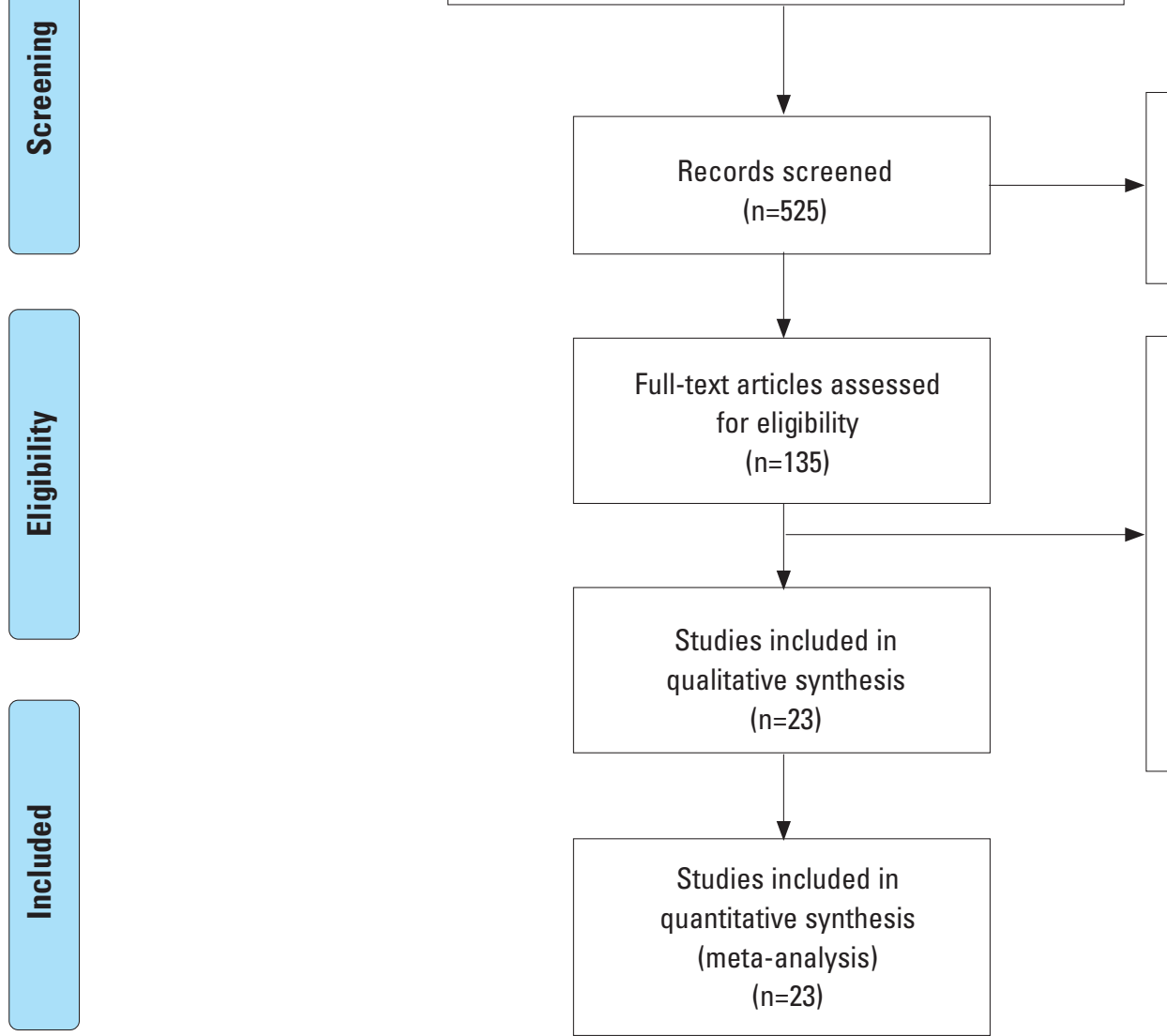

Records excluded based on inclusion criteria $(n=390)$

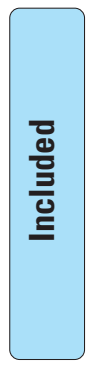

Studies included in

uantitative synthesis

$(n=23$

Figure 1. Preferred reporting items for systematic reviews and meta-analyses flow diagram showing detailed study selection process

ware 11.0 and GraphPad Prism 6.01. Pearson and Spearman correlations were used as appropriate according to the ShapiroWilk test to decide if the data were normally distributed.

\section{Results}

\section{Baseline characteristics of eligible studies}

After using keywords to search across different databases, a total of 981 articles ranging from 2000 to 2020 was retrieved. After carefully analyzing each individual literature, 23 satisfied studies were included for meta-analysis (Fig. 1). The successful rate of HBP was $83.64 \%$ (772/923) based on the 23 valid studies.
In those studies, there were 400 patients from a total of 574 patients with wide QRS duration (69.69\%) (QRSd >120 ms), and 452 patients from 565 patients showing reduced LVEF (88.86\%) (LVEF $<50 \%$ ). The baseline characteristics and discrepancy of preHBP and postHBP are displayed in Table 1 and Figure 2.

\section{Evaluation of ECG and echocardiographic characteristics}

A typical transition of ECG morphology was measured after the implantation of HBP. Paced QRS duration was reported in 21 studies, including 574 patients. The overall paced ORSd was significantly shorter than the baseline $(116.84 \pm 17.32 \mathrm{~ms}$ vs. $147.73 \pm 19.46 \mathrm{~ms}, \mathrm{p}<0.001$ ) (Table 2). Among those patients, ORSd 

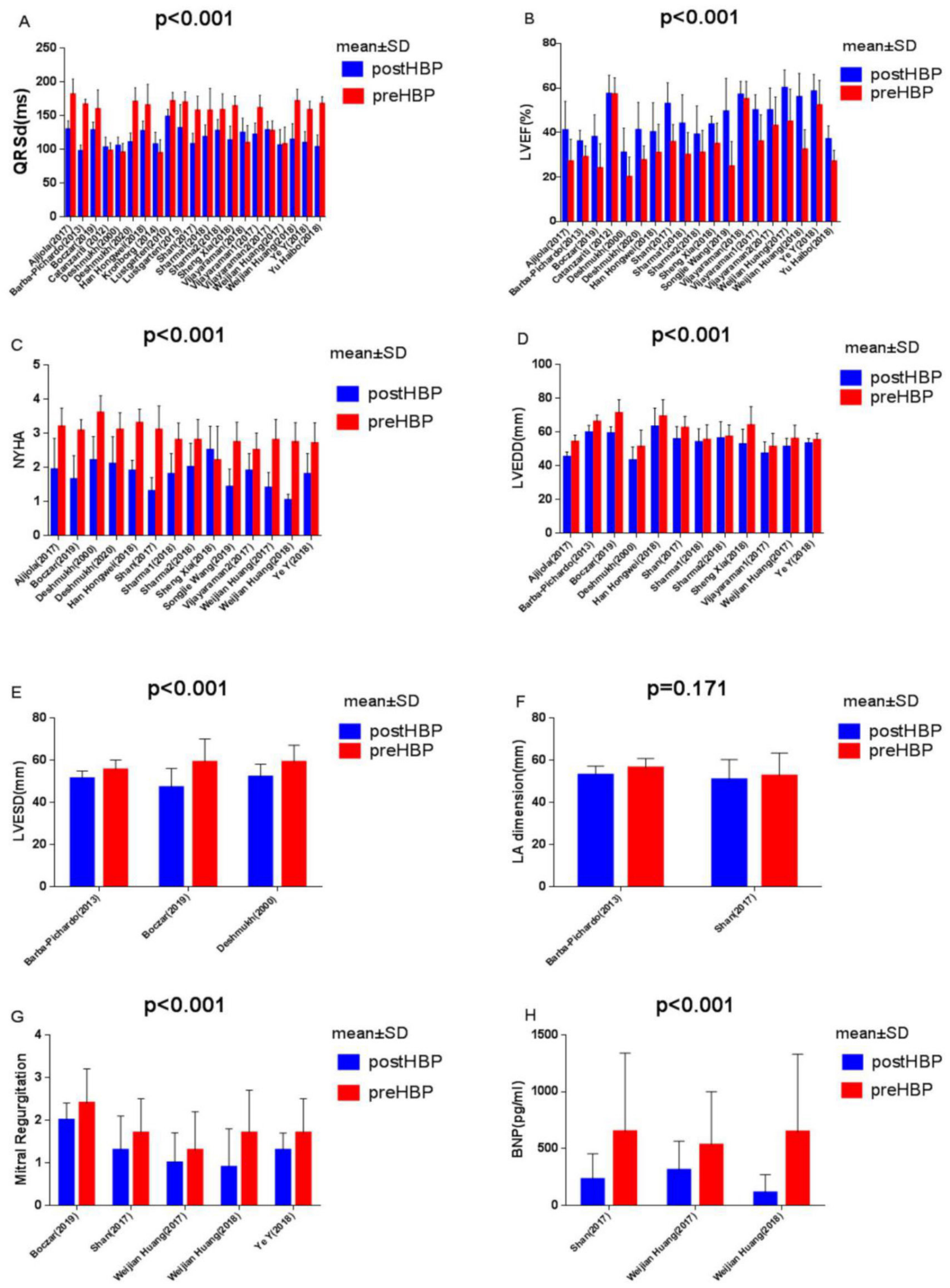

Figure 2. Comparison between postHBP and preHBP: (a) QRS duration; (b) left ventricular ejection fraction; (c) New York Heart Association; (d) left ventricular end-diastolic diameter; (e) left ventricular end-systolic diameter; (f) left arterial dimension; (g) mitral regurgitation; (h) brain natriuretic peptide 


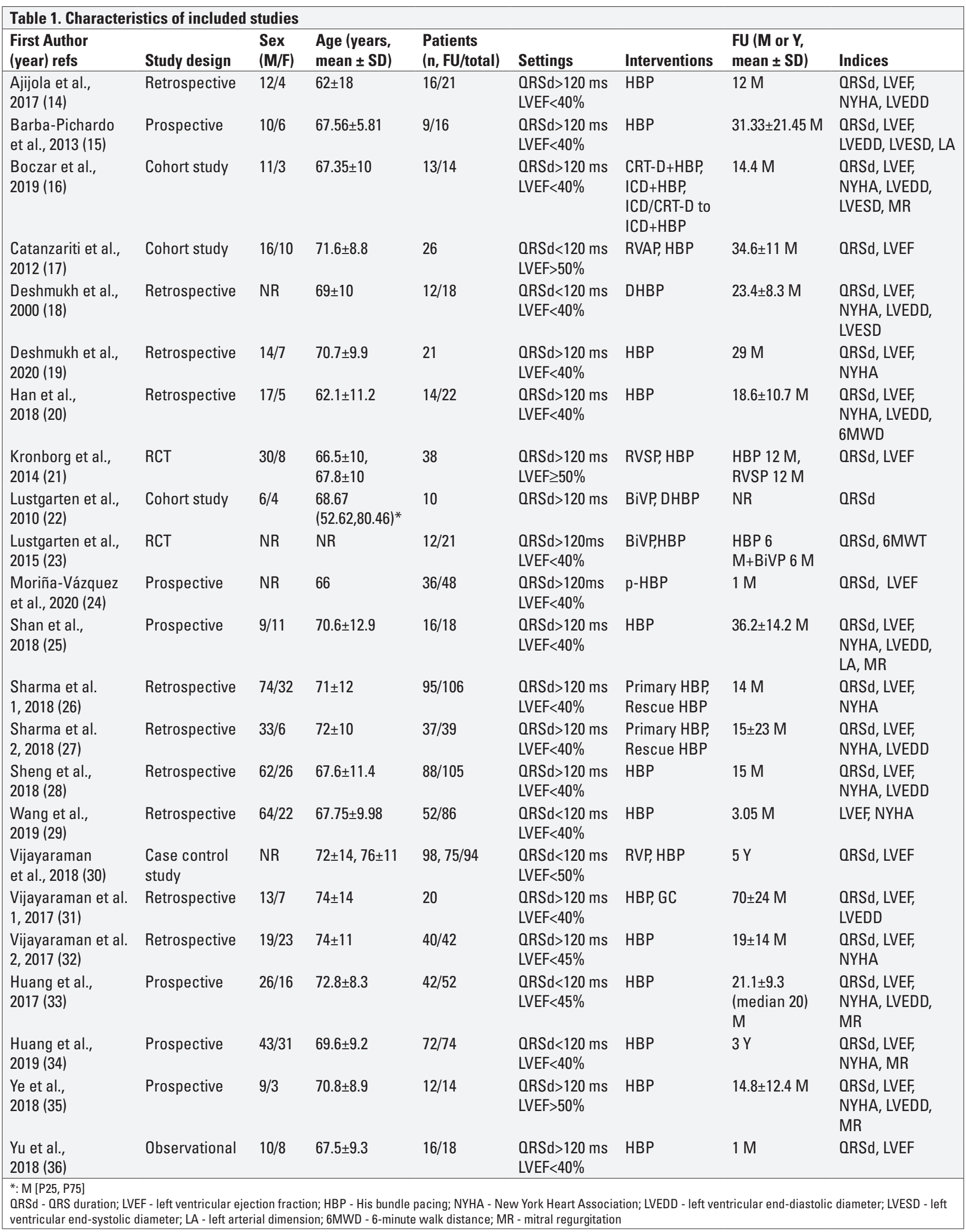




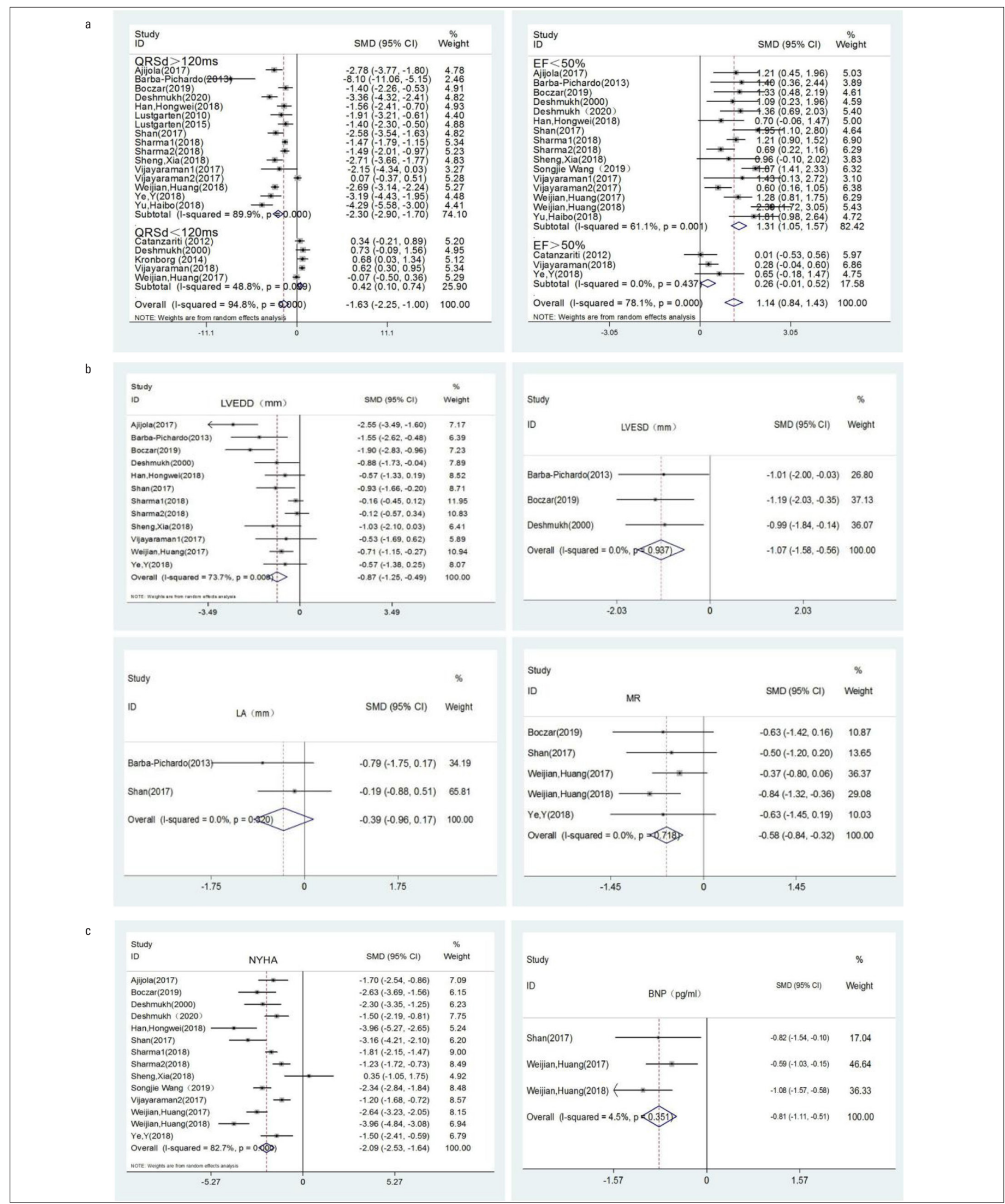

Figure 3. a) Subgroup analysis of forest plot showing changes between post- and preHBP for QRS duration and left ventricular ejection fraction. b) Forest plot showing changes between post and pre-HBP for left ventricular end-diastolic diameter, left ventricular end-systolic diameter, left arterial dimension, mitral regurgitation. c) Forest plot showing changes between post and pre His bundle pacing BP for New York Heart Association and brain natriuretic peptide 


\begin{tabular}{|c|c|c|c|c|c|c|c|}
\hline Parameters & $\boldsymbol{O}$ value & $\left.\right|^{2}$ value (\%) & $P$-value & SMD & $95 \% \mathrm{CI}$ & $Z$ value & $P$-value \\
\hline QRSd (ms) & 386.92 & 94.8 & 0.000 & -1.626 & $-2.254,-0.998$ & 5.08 & 0.000 \\
\hline NYHA & 74.99 & 82.7 & 0.000 & -2.088 & $-2.535,-1.641$ & 9.15 & 0.000 \\
\hline LVEDD (mm) & 41.84 & 73.7 & 0.000 & -0.871 & $-1.253,-0.489$ & 4.47 & 0.000 \\
\hline MR & 2.10 & 0.0 & 0.718 & -0.580 & $-0.841,-0.320$ & 4.37 & 0.000 \\
\hline BNP (pg/mL) & 2.09 & 4.5 & 0.351 & -0.804 & $-1.106,-0.509$ & 5.30 & 0.000 \\
\hline $\mathrm{LA}(\mathrm{mm})$ & 0.99 & 0.0 & 0.32 & -0.394 & $-0.957,0.170$ & 1.37 & 0.171 \\
\hline
\end{tabular}

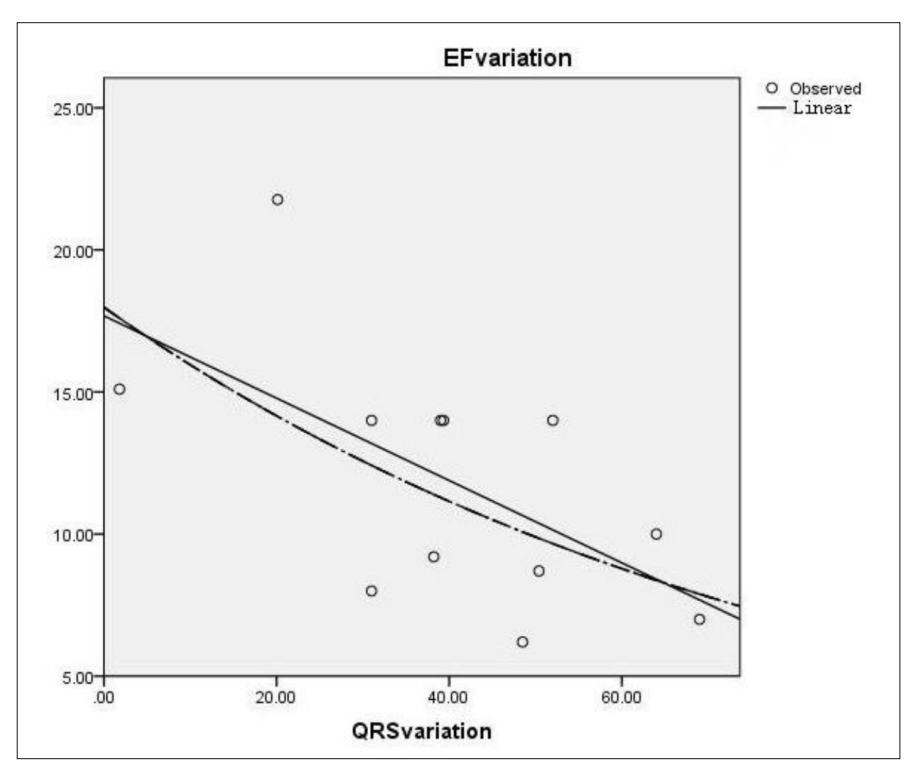

Figure 4. Fitting curve using 11 regression models to explore the relationship between left ventricular ejection fraction and QRS duration changes

$>120 \mathrm{~ms}$ at baseline was reported in 17 studies containing 400 patients. Subgroup analysis showed that there was significant difference in paced QRSd within baseline QRSd $>120 \mathrm{~ms}$ (SMD $2.30 ; 95 \% \mathrm{Cl} 2.90-1.70$ ), whereas limited difference was observed within the ORSd $<120 \mathrm{~ms}$ (SMD 0.42; 95\% $\mathrm{Cl} 0.10-0.74$ ) as shown in Figure 3a.

\section{Echocardiographic characteristics}

LVEF was reported in 19 studies, including 565 patients. Impressively, notable improvements of LVEF were identified within postHBP than in preHBP $(46.40 \pm 9.64 \%$ vs. $34.87 \pm 9.62 \%$, $\mathrm{p}<0.001)$. The subgroup analysis of the same group showed similar results as for LVpEF and LVrEF (SMD 0.26; 95\% CI 0.010.52 vs. SMD 1.31; $95 \%$ Cl 1.05-1.57) (Fig. 3a, Table 2). Structural cardiac changes observed through the echocardiogram were characterized as LVEDD, LVESD, MR, and LA. Interestingly, apart from LA showing limited improvement (SMD 0.39; 95\% CI 0.96-
$0.17)$, the rest of echocardiographic structural parameters indicated excellent recovery within the postHBP group, and the specific values of LVEDD (SMD 0.87; 95\% CI 1.25-0.49), LVESD (SMD 1.07; 95\% Cl 1.58-0.56), and MR (SMD 0.58; 95\% Cl 84-0.32) are shown in Figure $3 \mathrm{~b}$.

\section{Evaluation of cardiac function}

A total of 402 patients from 14 studies successfully received HBP treatment, correlating to NYHA functional class. Of these, 399 patients were followed up after the treatment. The results showed that after HBP treatment, NYHA improved significantly from $2.90 \pm 0.57$ at baseline to $1.78 \pm 0.58$ (SMD 2.09; $95 \% \mathrm{Cl} 2.53$ $1.64, \mathrm{p}<0.001)$. BNP reported in 3 studies $(25,33,34)$, reduced from $609.33 \pm 613.77 \mathrm{pg} / \mathrm{ml}$ to $216.6 \pm 212.8 \mathrm{pg} / \mathrm{ml}$. MWD demonstrated increasing trends within postHBP $(398.5 \pm 45 \mathrm{~m})$ than in preHBP $(248.5 \pm 57 \mathrm{~m})$. However, the result was inconclusive because of the limited data reported (Fig. 3c) $(20,23)$.

\section{Correlation and regression analyses}

Potential correlation between difference values of functional capacity and MR indices were similar to normal distributions, which were calculated using Pearson correlation. Intriguingly, no significant correlation between difference values of improvements was identified, and the specific values were QRS and NYHA, $r=0.104, p=0.775 ;$ QRS and LVEDD, $r=0.010$, $\mathrm{p}=0.977$; LVEF and NYHA, $r=0.463, \mathrm{p}=0.178$; LVEF and LVEDD, $r=-0.246, p=0.466 ;$ NYHA and LVEDD, $r=-0.125, p=0.730$. Meanwhile, if studies deviated from the data $(25,34)$ presented on scatter plots were excluded, possible correlation between LVEF and ORSd ( $r=-0.602, p=0.039$ ) was demonstrated. Curve fitting for 11 models was selected, and the linear regression model was chosen as the applicable mode according to the statistical results ( $\mathrm{R} 2=36.2 \%, \mathrm{p}=0.039)$ (Table 3 ). The regression equation was (Fig. 4).

\section{Analysis of sensitivity and quality assessment}

Sensitivity analysis suggested that studies $(30,34)$ showed that $\operatorname{CRSd}(30,35), \operatorname{LVEF}(36)$, and LVEDD were heterogeneous. 


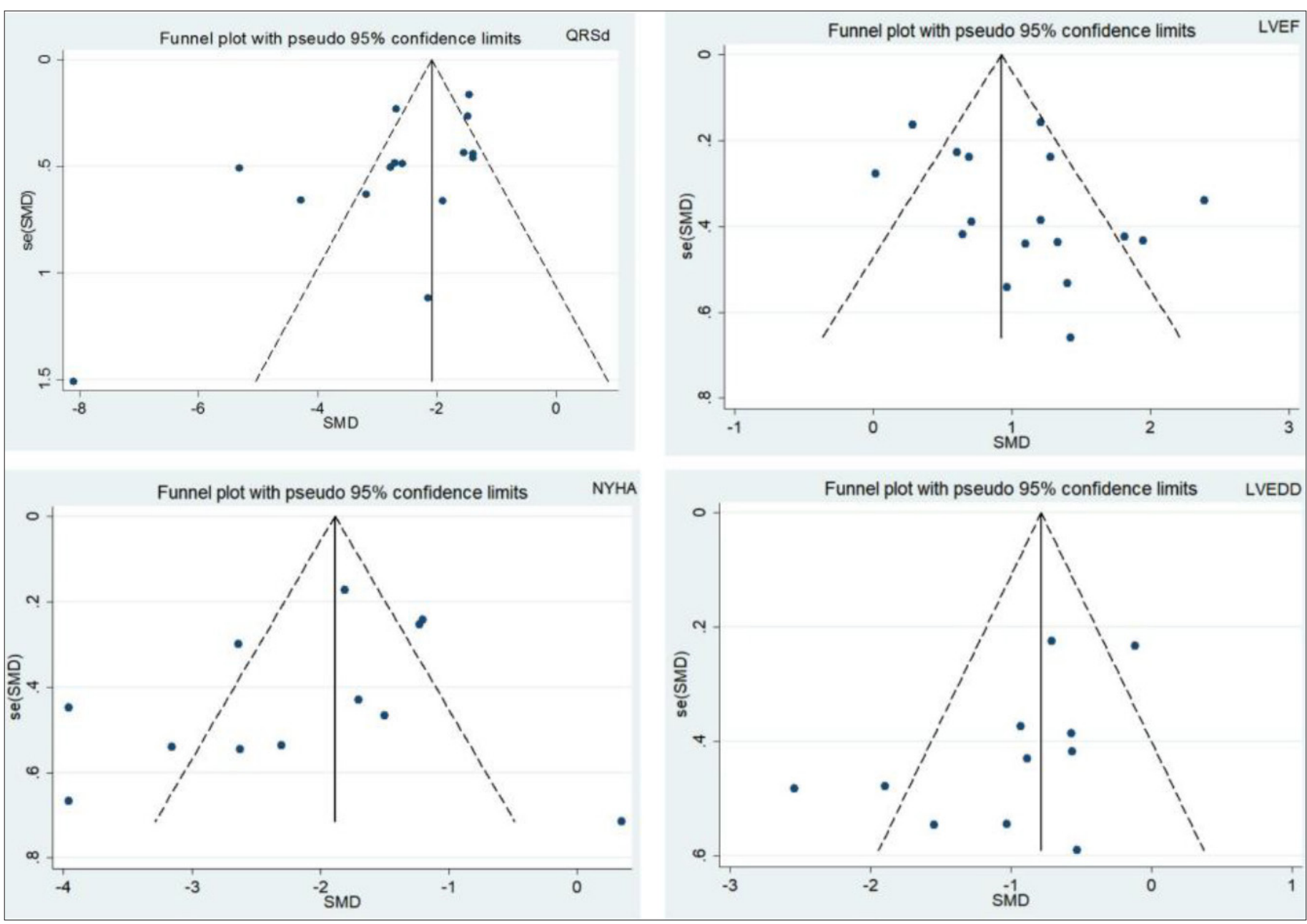

Figure 5. Funnel plot estimating publication bias for changes of main parameters following QRS duration, left ventricular ejection fraction, New York Heart Association, left ventricular end-diastolic diameter

Table 3. Model summary and parameter estimates in analyzing relation of LVEF and QRSd

Model summary and parameter estimates

Dependent variable: Ejection fraction variation

\begin{tabular}{|c|c|c|c|c|c|c|c|}
\hline \multirow[b]{2}{*}{ Equation } & \multicolumn{5}{|c|}{ Model summary } & \multicolumn{2}{|c|}{ Parameter estimates } \\
\hline & R square & $\mathbf{F}$ & df1 & df2 & Sig. & Constant & b1 \\
\hline Linear & .362 & 5.671 & 1 & 10 & .039 & 17.678 & -.145 \\
\hline Growth & .351 & 5.405 & 1 & 10 & .042 & 2.889 & -.012 \\
\hline Exponential & .351 & 5.405 & 1 & 10 & .042 & 17.979 & -.012 \\
\hline
\end{tabular}

However, the difference between the parameters diminished if one of included studies was excluded. Two randomized controlled trials $(21,23)$ were assessed separately because of their limited quantities but excellent data quality. Twenty-one observational studies were assessed by the Newcastle-Ottawa quality assessment (Table 4). No significant publication bias was revealed either by Egger's test with all the $p$ values $>0.05$ or the vertical funnel plot in Figure 5.

\section{Discussion}

A novel method for pacing through the His bundle site was discovered in canines by Scherlag for the first time in 1967 and applied to human patients in 1970 (37). Since then, the theory of physiologic pacing method had been intensively studied, and the procedural strategy for HBP has been optimized constantly. In 2000, Deshmukh et al. (18), for the first time, performed perma- 


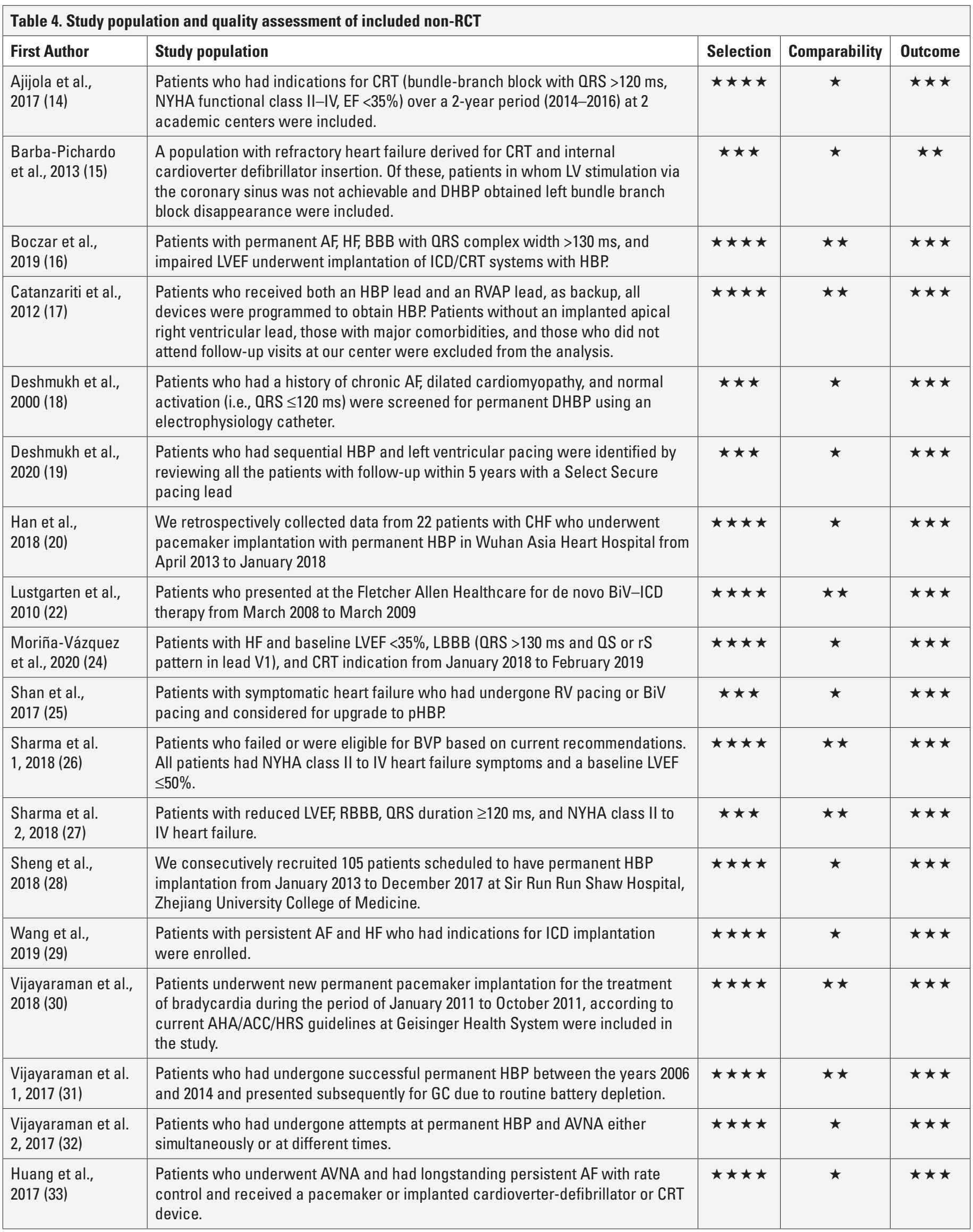




\begin{tabular}{|c|c|c|c|c|}
\hline First Author & Study population & Selection & Comparability & Outcome \\
\hline $\begin{array}{l}\text { Huang et al., } \\
2019 \text { (34) }\end{array}$ & $\begin{array}{l}\text { The inclusion criteria: (1) an ECG showing a wide QRS complex (>130 ms) and the } \\
\text { morphology of typical complete LBBB; (2) patients had heart failure with NYHA } \\
\text { Class II-IV symptoms; (3) patients were indicated for CRT or pacing therapy; (4) } \\
\text { patients were at least } 18 \text { years old and not pregnant. } \\
\text { Excluded: (1) non-specific intraventricular conduction delay or RBBB; (2) } \\
\text { patients with a life expectancy <12 months; (3) patients declining guideline- } \\
\text { indicated pacing therapy. }\end{array}$ & $\star \star \star \star$ & $\star$ & $\star \star \star$ \\
\hline Ye et al., 2018 (35) & $\begin{array}{l}\text { Patients with permanent AF and RVP, who were referred for pulse generator } \\
\text { change. Patients with RVP burden }>40 \% \text { were included. }\end{array}$ & $\star \star \star \star$ & $\star$ & $\star \star \star$ \\
\hline Yu et al., 2018 (36) & $\begin{array}{l}\text { Patients with CRT indications and HPCD from March } 2016 \text { to December } 2017 \text { in } \\
\text { General Hospital of Shenyang Military Region were enrolled in this study. }\end{array}$ & $\star \star \star \star$ & $\star$ & $\star \star \star$ \\
\hline
\end{tabular}

nent HBP on 14 patients. Impressively, 12 patients showed improved cardiac function after the treatment, despite 2 recorded deaths in the $8^{\text {th }}$ and $36^{\text {th }}$ months, indicating the clinical applicability and therapeutic effect of HBP.

Non-physiological dyssynchronous ventricular activation induced by the conventional pacing method, especially right ventricular apical pacing, accelerates the progression of ventricular remodeling, developing pacing-induced cardiomyopathy $(38,39)$. Although biventrivular pacing has been demonstrated as an effective way to lower the incidence of cardiac events, it is only applicable to patients with LVEF $<50 \%$ and atrioventricular block (40). Compared with conventional pacing methods including right ventricular pacing (RVP) and biventricular pacing (BiVP), HBP impulses Purkinje fiber directly instead of activating ventricular myocytes. In addition, by capturing the His bundle stimulus when depolarizing, HBP can accelerate the conduction speed through the ventricular electromechanical synchronization, unlike the pathway via myocardium (41). Moreover, direct HBP has been demonstrated as an alternative and effective method for CRT when the conventional method of left ventricular resynchronization via the coronary sinus fails (15).

In this study, we summarized the comprehensive characteristics of patients undergoing HBP and systematically evaluated the effect of postHBP compared with preHBP. The follow-up time involved in the analysis ranged from 1 month to 5 years. Most data were concluded from single-center observational studies, and only 2 RCTs $(21,23)$ were included, which may limit the data quality of this meta-analysis owing to the strict inclusion criteria for RCTs. However, our aim was to describe the electrocardiogram and echocardiographic characteristics of the preHBP and postHBP. In addition, the comparison between conventional pacing parameters (RVP, BiVP, etc.) and HBP parameters was out of the scope of this study.
A total of 923 patients were enrolled in the 23 studies selected. HBP was successfully performed on 772 patients with a success rate of $83.64 \%$, which is close to the success rate of $84.8 \%$ reported by Zanon et al. (42). In Zanon et al.'s (42) metaanalysis, 1,438 patients from 26 studies were included, and the clinical outcomes including pacing thresholds, complications, and mortality were excluded from this study. Among 923 patients included in this study, $400(69.69 \%)$ in 574 patients presented with wide QRS duration (QRSd >120 ms), and $452(88.86 \%$ ) in 565 patients had a reduced $\operatorname{LVEF}(<50 \%)$. Average $\mathrm{QRSd}$ at baseline was $147.73 \pm 19.46 \mathrm{~ms}$ and was $116.84 \pm 17.32 \mathrm{~ms}$ at follow-up, which was an average $31 \mathrm{~ms}$ drop in QRSd ( $<<0.001)$. Subgroup analysis further revealed that HBP could significantly rectify the conduction system, particularly within wide QRS complex (ORSd $>120 \mathrm{~ms}$ ). Sipahi et al. (43) reported that only patients with LBBB and systolic heart failure benefited from CRT, whereas patients with wide QRS did not benefit from CRT because of the conduction abnormalities. Tang et al. (44) reported that patients with LBBB had a better outcome than non-LBBB patients, and a potential correlation between benefit and ORS morphology was identified. We hypothesize this correlation between QRS and therapeutic effect can be a great clinical indicator to select suitable patients for HBP.

Average LVEF at baseline was $34.87 \pm 9.62 \%$, which increased to $46.4 \pm 9.64 \%$ at follow-up, an average $11.5 \%$ increase in LVEF $(p<0.001)$. Subgroup analysis demonstrated that LV contraction of postHBP improved significantly regardless of the baseline LVEF level, indicating patients with or without cardiac dysfunction can benefit from HBP. However, only 3 studies $(17,30,35)$ reported baseline LVEF $>50 \%$, and the lack of sufficient data may lead to inconclusive findings within this group. Therefore, further investigations and research are essential to provide additional information for conclusive result. The observed improvement based on echocardiogram in LVEDD, LVESD, and MR had been 
confirmed. After the mean follow-up time of 19.4 months for 399 patients, the NYHA functional class improved significantly from $2.90 \pm 0.57$ at baseline to $1.78 \pm 0.58(p<0.001)$ after the treatment. Interestingly, although there is a lack of sufficient data to accurately reflect the result, $6 \mathrm{MWD}$ data presented in limited studies showed significant increase. Together, this is evidence that restoration of ventricular electromechanical synchronization and reverse remodeling could contribute to improvement in cardiac function after HBP treatment.

Curve fitting indicated that different value of LVEF improved similar to that of QRS, with increasing of the ORSd difference value. LVEF showed a declining trend $(r=-0.602, p=0.039)$, whereas the different value correlation of the rest of the indices were not determined. Wang et al. (45) demonstrated a linear correlation between LVEF and LVEDD, but with a low $r$ value. Although there was no direct correlation between LVEF and LVEDD and other indices in this study, we believe that further studies with increased number of patients can reveal the potential connection between these indices.

Existing problems with the use of HBP including higher threshold, increased risk of failure to capture, prolonged procedural and fluoroscopy times, as well as reduced battery longevity $(12,46)$ have limited the wider use of HBP in current clinical setting. However, significant technological development has been made for implanting His bundle pacemakers. The high success rate $(83.64 \%)$ demonstrates that technological advancement can overcome the limitation of HBP, which may revolutionize the field of cardiac pacing.

\section{Study limitations}

This study had certain limitations. Limited quantitative experiment of life condition evaluations, such as 6MWD, were conducted with the selected studies; and inadequate results were included to demonstrate the associated complex adverse events. Furthermore, the endpoint events and complications of HBP were overlooked by this study. Therefore, because of the limited analysis of NYHA and 6MWD, the potential drawbacks of HBP drawn from the study could be a false positive.

\section{Conclusion}

HBP could reduce the QRS duration and improve cardiac function significantly in most patients. Although drawbacks were identified during long-term follow-up, HBP is still a promising approach owing to its applicability to a wider patient group with improved therapeutic effect, resulting in the improvement of life quality.

Institutional and financial support: This work was supported by Young Talent Fund (Fund No: QN1802).

Conflict of interest: None declared.

Peer-review: Externally and internally peer-reviewed.
Author contributions: Concept - M.L., F.R.; Design - M.L., F.R.; Supervision - H.S., D.Y.; Fundings - F.R.; Materials - K.Y., J.Z.; Data collection \&/or processing - J.T., K.Y.; Analysis \&/or interpretation - M.L.; Literature search - M.L.; Writing - M.L.; Critical review - H.S., D.Y., S.C.

\section{References}

1. Almufleh A, Marbach J, Chih S, Stadnick E, Davies R, Liu P, et al. Ejection fraction improvement and reverse remodeling achieved with Sacubitril/Valsartan in heart failure with reduced ejection fraction patients. Am J Cardiovasc Dis 2017; 7: 108-13.

2. Liu LW, Wu PC, Chiu MY, Tu PF, Fang CC. Sacubitril/Valsartan Improves Left Ventricular Ejection Fraction and Reverses Cardiac Remodeling in Taiwanese Patients with Heart Failure and Reduced Ejection Fraction. Acta Cardiol Sin 2020; 36: 125-32.

3. Ponikowski $P$, Voors AA, Anker SD, Bueno $H$, Cleland JGF, Coats AJS, et al. 2016 ESC Guidelines for the Diagnosis and Treatment of Acute and Chronic Heart Failure. Rev Esp Cardiol (Engl Ed) 2016; 69: 1167. [Article in English, Spanish]

4. Kim GH, Uriel N, Burkhoff D. Reverse remodelling and myocardial recovery in heart failure. Nat Rev Cardiol 2018; 15: 83-96. [Crossref]

5. Leyva F, Nisam S, Auricchio A. 20 years of cardiac resynchronization therapy. J Am Coll Cardiol 2014; 64: 1047-58. [Crossref]

6. Cleland JG, Daubert JC, Erdmann E, Freemantle N, Gras D, Kappenberger L, et al.; Cardiac Resynchronization-Heart Failure (CARE-HF) Study Investigators. The effect of cardiac resynchronization on morbidity and mortality in heart failure. $\mathrm{N}$ Engl $\mathrm{J}$ Med 2005; 352: 1539-49. [Crossref]

7. Bristow MR, Saxon LA, Boehmer J, Krueger S, Kass DA, De Marco T, et al.; Comparison of Medical Therapy, Pacing, and Defibrillation in Heart Failure (COMPANION) Investigators. Cardiacresynchronization therapy with or without an implantable defibrillator in advanced chronic heart failure. N Engl J Med 2004; 350: 2140-50. [Crossref]

8. Cvijić M, Antolič B, Klemen L, Zupan I. Repolarization heterogeneity in patients with cardiac resynchronization therapy and its relation to ventricular tachyarrhythmias. Heart Rhythm 2018; 15: 1784-90. [Crossref]

9. Ermis C, Seutter R, Zhu AX, Benditt LC, VanHeel L, Sakaguchi S, et al. Impact of upgrade to cardiac resynchronization therapy on ventricular arrhythmia frequency in patients with implantable cardioverterdefibrillators. J Am Coll Cardiol 2005; 46: 2258-63. [Crossref]

10. Medina-Ravell VA, Lankipalli RS, Yan GX, Antzelevitch C, MedinaMalpica NA, Medina-Malpica OA, et al. Effect of epicardial or biventricular pacing to prolong QT interval and increase transmural dispersion of repolarization: does resynchronization therapy pose a risk for patients predisposed to long OT or torsade de pointes? Circulation 2003; 107: 740-6. [Crossref]

11. Fish JM, Di Diego JM, Nesterenko V, Antzelevitch C. Epicardial activation of left ventricular wall prolongs $\mathrm{QT}$ interval and transmural dispersion of repolarization: implications for biventricular pacing. Circulation 2004; 109: 2136-42. [Crossref]

12. Saini $H$, Ellenbogen KA, Koneru JN. Future Developments in His Bundle Pacing. Card Electrophysiol Clin 2018; 10: 543-8. [Crossref]

13. Moher D, Shamseer L, Clarke M, Ghersi D, Liberati A, Petticrew M, et al.; PRISMA-P Group. Preferred reporting items for systematic review and meta-analysis protocols (PRISMA-P) 2015 statement. Syst Rev 2015; 4: 1. [Crossref]

14. Ajijola OA, Upadhyay GA, Macias C, Shivkumar K, Tung R. Permanent His-bundle pacing for cardiac resynchronization thera- 
py: Initial feasibility study in lieu of left ventricular lead. Heart Rhythm 2017; 14: 1353-61. [Crossref]

15. Barba-Pichardo R, Manovel Sánchez A, Fernández-Gómez JM, Moriña-Vázquez $\mathrm{P}$, Venegas-Gamero J, Herrera-Carranza M. Ventricular resynchronization therapy by direct His-bundle pacing using an internal cardioverter defibrillator. Europace 2013; 15: 83-8. [Crossref]

16. Boczar K, Sławuta A, Ząbek A, Dębski M, Vijayaraman P, Gajek J, et al. Cardiac resynchronization therapy with His bundle pacing. Pacing Clin Electrophysiol 2019; 42: 374-80. [Crossref]

17. Catanzariti D, Maines M, Manica A, Angheben C, Varbaro A, Vergara $G$. Permanent His-bundle pacing maintains long-term ventricular synchrony and left ventricular performance, unlike conventional right ventricular apical pacing. Europace 2012; 15: 546-53. [Crossref]

18. Deshmukh P, Casavant DA, Romanyshyn M, Anderson K. Permanent, direct His-bundle pacing: a novel approach to cardiac pacing in patients with normal His-Purkinje activation. Circulation 2000; 101: 869-77. [Crossref]

19. Deshmukh A, Sattur S, Bechtol T, Heckman LIB, Prinzen FW, Deshmukh P. Sequential His bundle and left ventricular pacing for cardiac resynchronization. J Cardiovasc Electrophysiol 2020; 31: 2448-54. [Crossref]

20. Han H, Su X, Yang X, Wang S, Liu Z, Zhong R. Permanent His bundle pacing improving cardiac function in the patients with chronic systolic heart failure. Chinese Journal of Cardiac Arrhythmias 2018; 22: 111-6.

21. Kronborg MB, Mortensen PT, Poulsen SH, Gerdes JC, Jensen HK, Nielsen JC. His or para-His pacing preserves left ventricular function in atrioventricular block: a double-blind, randomized, crossover study. Europace 2014; 16: 1189-96. [Crossref]

22. Lustgarten DL, Calame S, Crespo EM, Calame J, Lobel R, Spector PS. Electrical resynchronization induced by direct His-bundle pacing. Heart Rhythm 2010; 7: 15-21. [Crossref]

23. Lustgarten DL, Crespo EM, Arkhipova-Jenkins I, Lobel R, Winget J, Koehler $\mathrm{J}$, et al. His-bundle pacing versus biventricular pacing in cardiac resynchronization therapy patients: A crossover design comparison. Heart Rhythm 2015; 12: 1548-57. [Crossref]

24. Moriña-Vázquez $P$, Moraleda-Salas MT, Manovel-Sánchez AJ, Fernández-Gómez JM, Arce-Léon Á, Venegas-Gamero J, et al. Early improvement of left ventricular ejection fraction by cardiac resynchronization through His bundle pacing in patients with heart failure. Europace 2020; 22: 125-32. [Crossref]

25. Shan P, Su L, Zhou X, Wu S, Xu L, Xiao F, et al. Beneficial effects of upgrading to His bundle pacing in chronically paced patients with left ventricular ejection fraction $<50$. Heart Rhythm 2018; 15: 405-12. [Crossref]

26. Sharma PS, Dandamudi G, Herweg B, Wilson D, Singh R, Naperkowski A, et al. Permanent His-bundle pacing as an alternative to biventricular pacing for cardiac resynchronization therapy: A multicenter experience. Heart Rhythm 2018; 15: 413-20. [Crossref]

27. Sharma PS, Naperkowski A, Bauch TD, Chan JYS, Arnold AD, Whinnett $\mathrm{Zl}$, et al. Permanent His Bundle Pacing for Cardiac Resynchronization Therapy in Patients With Heart Failure and Right Bundle Branch Block. Circ Arrhythm Electrophysiol 2018; 11: e006613. [Crossref]

28. Sheng X, Pan Y, Zhang J, Ye Y, Jiang D, Yang Y, et al. Long-term safety and feasibility of permanent His bundle pacing. Chin $\mathrm{J}$ Cardiac Arrhyth 2018; 22: 100-4.
29. Wang S, Wu S, Xu L, Xiao F, Whinnett Zl, Vijayaraman P, et al. Feasibility and Efficacy of His Bundle Pacing or Left Bundle Pacing Combined With Atrioventricular Node Ablation in Patients With Persistent Atrial Fibrillation and Implantable CardioverterDefibrillator Therapy. J Am Heart Assoc 2019; 8: e014253. [Crossref]

30. Vijayaraman P, Naperkowski A, Subzposh FA, Abdelrahman M, Sharma PS, Oren JW, et al. Permanent His-bundle pacing: Longterm lead performance and clinical outcomes. Heart Rhythm 2018; 15: 696-702. [Crossref]

31. Vijayaraman P, Dandamudi G, Lustgarten D, Ellenbogen KA. Permanent His bundle pacing: Electrophysiological and echocardiographic observations from long-term follow-up. Pacing Clin Electrophysiol 2017; 40: 883-91. [Crossref]

32. Vijayaraman P, Subzposh FA, Naperkowski A. Atrioventricular node ablation and His bundle pacing. Europace 2017; 19(suppl_4): iv10-6. [Crossref]

33. Huang W, Su L, Wu S, Xu L, Xiao F, Zhou X, et al. Benefits of Permanent His Bundle Pacing Combined With Atrioventricular Node Ablation in Atrial Fibrillation Patients With Heart Failure With Both Preserved and Reduced Left Ventricular Ejection Fraction. J Am Heart Assoc 2017; 6: e005309. [Crossref]

34. Huang W, Su L, Wu S, Xu L, Xiao F, Zhou X, et al. Long-term outcomes of His bundle pacing in patients with heart failure with left bundle branch block. Heart 2019; 105: 137-43. [Crossref]

35. Ye Y, Zhang Z, Sheng X, Wang B, Chen S, Pan Y, et al. Upgrade to his bundle pacing in pacing-dependent patients referred for pulse generator change: Feasibility and intermediate term follow up. Int J Cardiol 2018; 260: 88-92. [Crossref]

36. Yu H, Liang Y, Wang N, Liang Z, Xu B, Gao Y, et al. The application of His bundle pacing in patients with heart failure and His-Purkinje conduction disease. Chin J Cardiac Arrhyth 2018; 22: 105-10.

37. Narula OS, Scherlag BJ, Samet P. Pervenous pacing of the specialized conducting system in man. His bundle and A-V nodal stimulation. Circulation 1970; 41: 77-87. [Crossref]

38. Thambo JB, Bordachar P, Garrigue S, Lafitte S, Sanders P, Reuter $S$, et al. Detrimental ventricular remodeling in patients with congenital complete heart block and chronic right ventricular apical pacing. Circulation 2004; 110: 3766-72. [Crossref]

39. Dreger H, Maethner K, Bondke H, Baumann G, Melzer C. Pacinginduced cardiomyopathy in patients with right ventricular stimulation for $>15$ years. Europace 2012; 14: 238-42. [Crossref]

40. Curtis AB, Worley SJ, Adamson PB, Chung ES, Niazi I, Sherfesee L, et al.; Biventricular versus Right Ventricular Pacing in Heart Failure Patients with Atrioventricular Block (BLOCK HF) Trial Investigators. Biventricular pacing for atrioventricular block and systolic dysfunction. N Engl J Med 2013; 368: 1585-93. [Crossref]

41. Su L, Xu L, Wu SJ, Huang WJ. Pacing and sensing optimization of permanent His-bundle pacing in cardiac resynchronization therapy/implantable cardioverter defibrillators patients: value of integrated bipolar configuration. Europace 2016; 18: 1399-405. [Crossref]

42. Zanon F, Ellenbogen KA, Dandamudi G, Sharma PS, Huang W, Lustgarten DL, et al. Permanent His-bundle pacing: a systematic literature review and meta-analysis. Europace 2018; 20: 1819-26. [Crossref]

43. Sipahi I, Chou JC, Hyden M, Rowland DY, Simon DI, Fang JC. Effect of QRS morphology on clinical event reduction with cardiac resynchronization therapy: meta-analysis of randomized controlled trials. Am Heart J 2012; 163: 260-7. [Crossref] 
44. Tang AS, Wells GA, Talajic M, Arnold MO, Sheldon R, Connolly S, et al.; Resynchronization-Defibrillation for Ambulatory Heart Failure Trial Investigators. Cardiac-resynchronization therapy for mild-tomoderate heart failure. N Engl J Med 2010; 363: 2385-95. [Crossref]

45. Wang Y, Zhou R, Lu C, Chen 0, Xu T, Li D. Effects of the Angiotensin-Receptor Neprilysin Inhibitor on Cardiac Reverse
Remodeling: Meta-Analysis. J Am Heart Assoc 2019; 8: e012272. [Crossref]

46. Kronborg MB, Mortensen PT, Poulsen SH, Gerdes JC, Jensen HK, Nielsen JC. His or para-His pacing preserves left ventricular function in atrioventricular block: a double-blind, randomized, crossover study. Europace 2014; 16: 1189-96. [Crossref] 